\title{
Highly birefringent do-octagonal photonic crystal fibers with ultra flattened zero dispersion for supercontinuum generation
}

\author{
Pranaw Kumar (D, Kokou Firmin Fiaboe (D), Jibendu Sekhar Roy \\ KIIT, Bhubaneswar, India \\ kumarpranaw9@gmail.com,fiaboefirmin@gmail.com,drjsroy@rediffmail.com
}

\begin{abstract}
Photonic crystal fiber (PCF) structures with do-octagonal geometry have been studied. These do-octagonal PCF structure have smaller circular holes arranged in rhombic fashion at its centre. Moreover, these small holes are doped with materials like butanol, ethanol, methanol and propanol. Do-octagonal PCF structures doped with methanol and air filled structure report very high birefringence. Ultra flattened zero dispersion has been achieved by all the simulated structures. Besides, low confinement loss and large nonlinearity have also been reported. Numerical simulation for supercontinuum generation has been performed. Supercontinuum spectra obtained for peak power $1 \mathrm{~kW}, 2 \mathrm{~kW}, 5 \mathrm{~kW}$ and $10 \mathrm{~kW}$ are $650 \mathrm{~nm}, 950 \mathrm{~nm}, 1450 \mathrm{~nm}$ and $2050 \mathrm{~nm}$ respectively.
\end{abstract}

Index Terms - Photonic crystal fibers, birefringence, supercontinuum generation, dispersion, confinement loss, nonlinearity.

\section{INTRODUCTION}

Optical properties in PCF can be easily tailored to obtain desire results. It can be achieved by designing a particular pattern or arrangement of holes and also by changing the dimension of the hole. Moreover pitch factor of hole and the number of hole in the cladding region can also result desired changes. Photonic crystal fiber due to their extraordinary properties compared to standard optical fibers has drawn the attention of many researchers[1]-[4]. These properties include chromatic dispersion [5], birefringence [6], ultra low loss [7], endless single mode propagation [8], large nonlinear co-efficient [9] and effective mode area [10]. In conventional fiber, achieved birefringences are very low due to very low refractive index contrast. Different to this, PCF are having large index contrast and design flexibility as well. Hence very high value of birefringence can be easily achieved in PCF [11]. Researchers have reported high birefringence by using squeezed crystal lattice. In this structure number of holes are different along two orthogonal axes [12]. Researchers have also used elliptical holes to obtain high birefringence [13]. Lyngso et al [14] reported polarization maintaining index guiding PCF. Cho et al shown large birefringence in plastic PCF [15]. Highly birefringent PCFs can be obtained by adopting two ways. First way is to break the symmetry in the cladding region. And other way is to introduce asymmetry in a porous core. Highly birefringent PCFs have wide application in optic sensor, Précised optical instruments, and high transmission speed, optical communication system. Control over chromatic dispersion in PCF is vital for their partial application. Again there is a tradeoff between high 
birefringence and dispersion with low losses. Large index contrast sometimes result excessive chromatic dispersion. Hence to make a control over dispersion with high birefringence has always been a challenge for the researchers. Several PCF structures with zero dispersion and high birefringence have been achieved by the researchers [16]-[18]. To achieve more significant result PCF with arrangement like square [19], rectangular [20], octagonal [21], decagonal [22], and do-decagonal [23] have been investigated. Moreover, various PCF structures with nanometric holes have been reported [24]-[28]. PCF structures with such holes have been selectively filled or fully filled with liquids, gases and other materials [29]-[32]. Very tight confinement of optical mode in core results large non linearity. It can be achieved by reducing the core area. It can also be obtained by increasing the index contrast between core and cladding. The contrast can be increased by use of soft glass material. Supercontinuum generation is an inherent property of nonlinear optics. It has wide application in pulse compression, coherence tomography and spectroscopy meteorology [33]-[34]. Basically, supercontinuum generation, in nonlinear process produces broadband light. Interaction of short and intense pulses data output of nano band sources 81elps in achieving this. Zero ultra flattened dispersion is the primary need of achieving a broadband supercontinuum generation. Ranka et al was the first to demonstrated supercontinuum generation [35]. Supercontinuum spectrum are generated by pumping ultra short pulses in fiber whose wavelength lie in dispersion regime close to zero dispersion wavelength. Razak et al achieved large nonlinearity with octagonal PCF [36]. Moreover Camerlengo et al introduced a W-type index profile PCF with nonlinearity $0.82 \mathrm{~W}^{-1} \mathrm{~m}^{-1}$ at zero dispersion wavelengths [37].

In this work, do-octagonal PCF structures doped with material of alcoholic group have been studied. Initially, a hexagonal PCF has been designed. Later a do-octagonal shaped core has been made by introducing defects at the centre. This defect is made by removing holes at the centre of fiber. After that new holes, smaller in dimension has been arranged in a rhombic fashion. The structure has a rhombic arrangement of holes fill with materials of alcoholic group and air. Alcoholic material like butanol, ethanol, methanol and propanol has been used. The structure report ultra flattened zero dispersion at visible range and at infrared region. Birefringence shown by the structure is much higher and is of the order of $10^{-1}$. PCF structure doped with methanol reported highest birefringence. Moreover this structure reported ultra low confinement loss and very large nonlinear coefficient. Supercontinuum generation has also been generated at a wavelength of $1250 \mathrm{~nm}$.

\section{DESIGN OF DO-OCTAGONAL PCF STRUCTURE}

Six ring hexagonal PCF structures have been studied. The PCF structure has holes doped with different material and air arranged in a rhombic fashion at the centre. These holes have much smaller dimension than the holes arranged in the external six rings. Material used for doping are butanol, ethanol, methanol and propanol. The schematic diagram of the investigated structure is shown in Fig. 1(a). Fig. 1(b) shows the three dimensional view of the same investigated structure. Table I shows the description of all five PCF structure simulated in this work. 


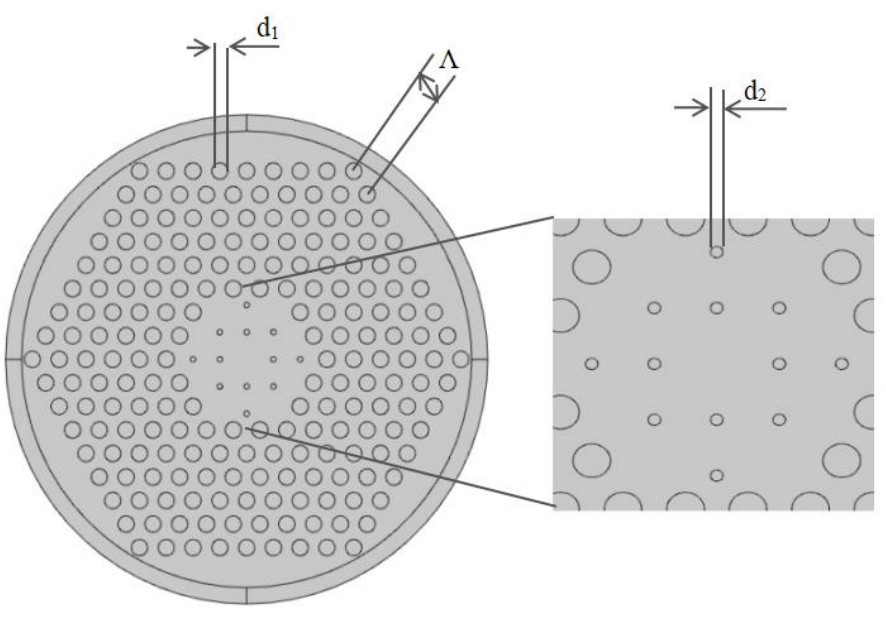

(a)

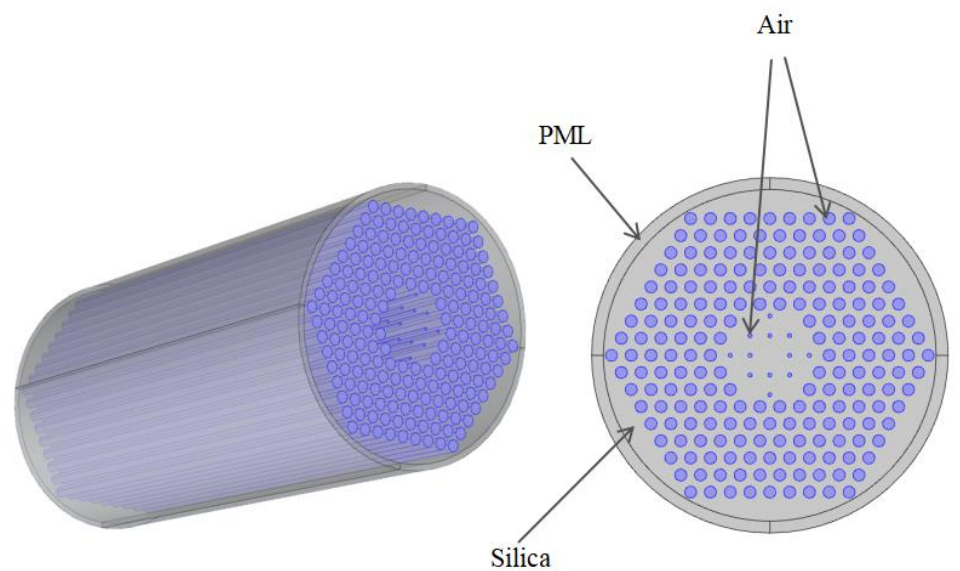

(b)

Fig. 1. (a) Designed do-octagonal PCF structure, (b) 3-D view of proposed PCF structure

TABLE I. DESCRIPTION OF SIMULATED PCF STRUCTURES

\begin{tabular}{|c|c|}
\hline PCF Structures & Descriptions \\
\hline Silica_Air & $\begin{array}{l}\text { This structure has six rings of holes of circular dimension filled with air. At centre it has smaller } \\
\text { circular holes arranged in rhombic fashion filled with air. Smaller circular holes have diameter } \\
\text { of } \mathrm{d} 2=0.2^{*} \wedge \text {, where } \wedge=1 \mu \mathrm{m} \text {. External six rings have air holes of diameter } \mathrm{d} 1=0.6^{*} \wedge \text {. }\end{array}$ \\
\hline Silica_Butanol & $\begin{array}{l}\text { This structure has six rings of holes of circular dimension filled with air. At centre it has smaller } \\
\text { circular holes arranged in rhombic fashion filled with butanol. Smaller circular holes have } \\
\text { diameter of } \mathrm{d} 2=0.2 * \wedge \text {, where } \wedge=1 \mu \mathrm{m} \text {. External six rings have air holes of diameter } \mathrm{d} 1=0.6^{*} \wedge \text {. }\end{array}$ \\
\hline Silica_Ethanol & $\begin{array}{l}\text { This structure has six rings of holes of circular dimension filled with air. At centre it has smaller } \\
\text { circular holes arranged in rhombic fashion filled with ethanol. Smaller circular holes have } \\
\text { diameter of } \mathrm{d} 2=0.2^{*} \wedge \text {, where } \wedge=1 \mu \mathrm{m} \text {. External six rings have air holes of diameter } \mathrm{d} 1=0.6^{*} \wedge \text {.. }\end{array}$ \\
\hline Silica_Methanol & $\begin{array}{l}\text { This structure has six rings of holes of circular dimension filled with air. At centre it has smaller } \\
\text { circular holes arranged in rhombic fashion filled with methanol. Smaller circular holes have } \\
\text { diameter of } \mathrm{d} 2=0.2 * \wedge \text {, where } \wedge=1 \mu \mathrm{m} \text {. External six rings have air holes of diameter } \mathrm{d} 1=0.6^{*} \wedge \text {. }\end{array}$ \\
\hline Silica_Propanol & $\begin{array}{l}\text { This structure has six rings of holes of circular dimension filled with air. At centre it has smaller } \\
\text { circular holes arranged in rhombic fashion filled with propanol. Smaller circular holes have } \\
\text { diameter of } \mathrm{d} 2=0.2 * \wedge \text {, where } \wedge=1 \mu \mathrm{m} \text {. External six rings have air holes of diameter } \mathrm{d} 1=0.6^{*} \wedge \text {. }\end{array}$ \\
\hline
\end{tabular}


Full vector finite element method (FEM) numerical technique have been adopted to analyse the different propagation characteristics of PCF. First FEM processes complex structured PCFs into homogeneous subspaces. Secondly, it is computed with Maxwell's vector equation as given by equation (1) [38].

$$
\begin{aligned}
& \nabla *\left([s]^{-1} \nabla * E\right)-k_{0}^{2} n^{2}[s] E=0 \\
& {[s]=\left(\begin{array}{ccc}
s_{y} / s_{x} & 0 & 0 \\
0 & s_{x} / s_{y} & 0 \\
0 & 0 & s_{x} s_{y}
\end{array}\right)}
\end{aligned}
$$

Where [s] is perfectly matched layer matrix of dimension $3 X 3$. It includes even parameters $S_{x}$ and $S_{y}$. Electric vector is denoted by ' $\mathrm{E}$ '. Wave number in vacuum is obtained as:

$$
K_{0}=2 \pi / \lambda
$$

A circularly perfectly matched layer, boundary condition having thickness $10 \%$ of the fiber radius have been used to absorb the scattered light towards the surface of the fiber. Propagation constant $(\beta)$ and effective refractive index at different wavelength $(\lambda)$ are provided by the simulating software COMSOL Multiphysics 5.2. These are represented as

$$
\beta=n_{\text {eff }} K_{0}
$$

Modal birefringence defined as the difference between two polarized modes, is considered to play important role in determining PCFs to work as sensors. Mathmatically, it can be expressed as [30]:

$$
B=\left|\operatorname{Re}\left(n_{\text {effective }}^{x}-n_{\text {effective }}^{y}\right)\right|
$$

$n_{\text {effective }}^{x}$ and $n_{\text {effective }}^{y}$ shows the effective refractive indices of $x$ polarized and $y$ polarized mode respectively.

Again, obtained effective refractive index of the guided fundamental modes at different wavelengths helps in calculating chromatic dispersion parameters of PCF by using the following mathematical expressions [39]:

$$
\mathrm{D}(\lambda)=\frac{-2 \pi \mathrm{c}}{\lambda^{2}} \beta_{2}=\frac{-\lambda}{c} \frac{d^{2} n_{\text {eff }}}{d \lambda^{2}}
$$

The cross sectional area of mode field, over which the field gets confined along the fiber during its propagation is termed as effective area $\left(\mathrm{A}_{\text {eff }}\right)$. High optical intensities are the results of smaller effective area. Hence, PCF with small effective area results large nonlinear coefficient $(\gamma)$ [40].

$$
\mathrm{A}_{e f f}=\left(\int_{-\infty}^{\infty} \int_{-\infty}^{\infty}|E|^{2} d x d y\right)^{2} / \int_{-\infty}^{\infty} \int_{-\infty}^{\infty}|E|^{4} d x d y
$$




$$
\gamma=\frac{2 \pi n_{2}}{\mathrm{~A}_{e f f} \lambda}
$$

Where $|E|$ is the transverse electric field. $n_{2}=3.0 \times 10^{-20} \mathrm{~m}^{2} \mathrm{~W}^{-1}$, is the nonlinear refractive index of silica used. $n_{2}$ decides the degree to which non linear effects occur when light with high intensity propagate into the fiber.

Modes having leaky nature, together with non-perfect structure of PCFs result confinement loss. It is an extra form of loss which occurs in PCFs, usually made up of silica. These modes get leaky due to the finite lattice structure of PCFs. Confinement loss is calculated by considering imaginary part of the refractive index. It is calculated using formula [40]:

$$
L\left(\frac{d B}{m}\right)=\frac{40 \pi}{\ln (10) \lambda} \operatorname{Im}\left(n_{\text {eff }}\right)=8.686 K_{0} \operatorname{Im}\left[n_{\text {eff }}\right]
$$

Investigation of supercontinuum generation in the design fiber has been made. Modified nonlinear Schrodinger equation describes the mathematical model of supercontinuum generation. Schrodinger equation has different linear and nonlinear effects. This equation is solved using Split step Fourier method [41-43].

$$
\frac{\partial}{\partial Z} A(Z, T)=\frac{-\alpha(\omega)}{2} A(Z, T)+\sum_{n \geq 2} \beta_{n} \frac{i^{n+1}}{n !} \frac{\partial^{n}}{\partial t^{n}} A(Z, T)+i \gamma\left(1+\frac{i}{\omega_{0}} \frac{\partial}{\partial T}\right) \int_{-\infty}^{\infty} R\left(T^{\prime}\right)\left|A\left(Z, T-T^{\prime}\right)\right|^{2} d T^{\prime}
$$

Where A $(Z, T)$ represents slow varying envelope of the electric field of the optical pulse. The pulses move in a frame of reference along the z- direction at the pump frequency of the group velocity. $\alpha$ represent the attenuation constant of the fiber. $\beta_{\mathrm{n}}$ is the $\mathrm{n}^{\text {th }}$ order propagation constant at the center frequency $\omega_{\mathrm{o}} . R(T)$ shows the nonlinear response function . It includes Raman contribution. It is defined as

$$
R(T)=\left(1-f_{r}\right) \delta(T)+f_{r} h_{r}(T)
$$

$f_{r}$ represent fractional contribution of the delay Raman response . Its value is taken to be $0.18 . h_{r}$ represent form of Raman response function and it is calculated as

$$
h_{r}(T)=\frac{\tau_{1}^{2}+\tau_{2}^{2}}{\tau_{1} \tau_{2}^{2}} \exp \left(-\frac{T}{\tau_{2}}\right) \sin \left(\frac{-T}{\tau_{1}}\right)
$$

Where $\tau_{1}=12.2 f s$ and $\tau_{2}=32 f s$ use for silica . Possibility of cross phase modulation between pulses of two different polarizations are minimized as the assume input pulse with either posses vertical or horizontal polarization during launching into the fiber. 


\section{SIMULATION AND RESULTS}

Simulated PCF structures have circular holes arranged in rhombic fashion. External six rings are arranged in hexagonal arrangements. Dimension of six rings with hexagonal arrangements have diameter $d 1$, where $d 1=0.6^{*} \wedge$. Here $\wedge$ is the pitch factor and its value taken is $1.0 \mu \mathrm{m}$. However holels arranged in rohmbic fashion have smaller diameter $\mathrm{d} 2$, where $\mathrm{d} 2=0.2 * \wedge$. Designed PCFs have been simulated by finite element method (FEM) method of COMSOL Multiphysics 5.2 software.

Investigated PCF structures report highly birefringent behavior. Do-octagonal structure with air hole and do-octagonal PCF structure dopped with methanol report highest birefringence in comparison to other PCF structures studied in this work. Achieved birefringence for these two PCF structure is of the order of $10^{-1}$. Microstructured core are feasible to obtain enhanced birefringence. Further increasing or decreasing the diameter of air hole in the microstructure core and reducing the size of spacing between two consecutive holes (pitch factor) results much higher birefringence. Methanol is an active, volatile , toxic and flammable raw material for the production of synthetic resin and plastic. Advantage of photonic crystal slabs doped with methanol solve the problem of accuracy, sensitivity and security [44], [45]. Moreover researchers have reported a highly birefringence spiral photonic crystal fiber for gas sensing application [46] and Shengsi et al have reported a new two dimensional photonic slab with methanol doped photonic crystal slab [47]. Fig. 2 shows birefringence behavior at diffrent wavelengths. Fig. 3 shows linearily polarized mode of the simulated structure. Due to rhombic arrangement of smaller holes, achieved birefringence at higher wavelengths is much higher.

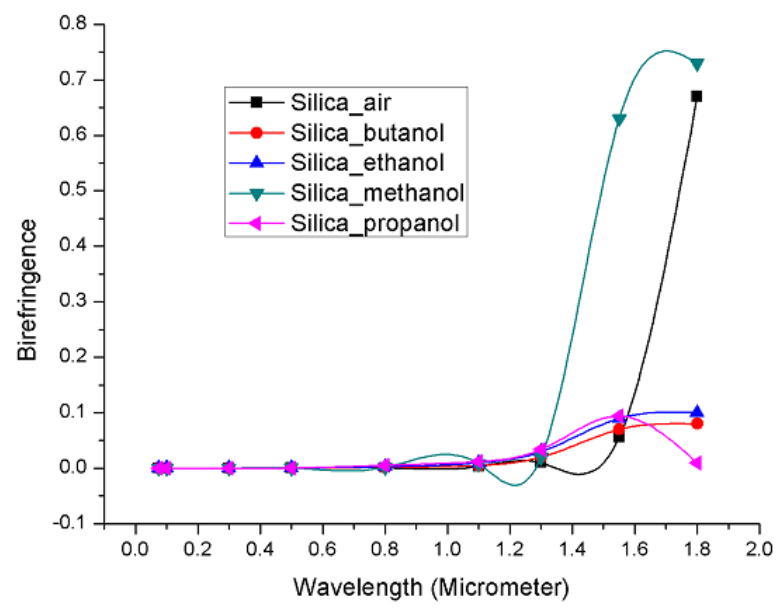

Fig. 2. Birefringence behavior.

Do-octagonal PCF structure has shown ultra flattened zero dispersion. From visible range to far infrared region, all the five PCF structure have shown flattened zero dispersion. Group velocity dispersion in standard fiber is dominated by the dispersion of bulk silica. However in photonic crystal fiber design parameters like hole diameter, center to center spacing and geometry of holes enable flexibility in designing PCF to control over dispersion [48], [49]. 


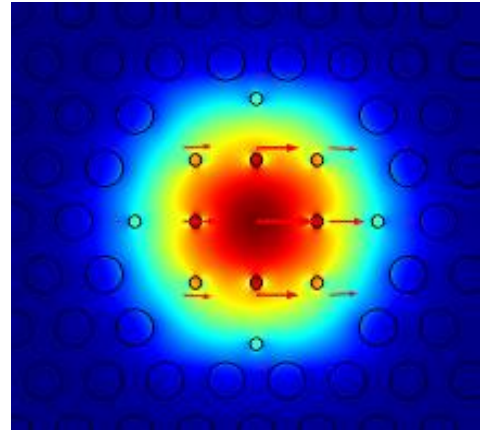

(a)

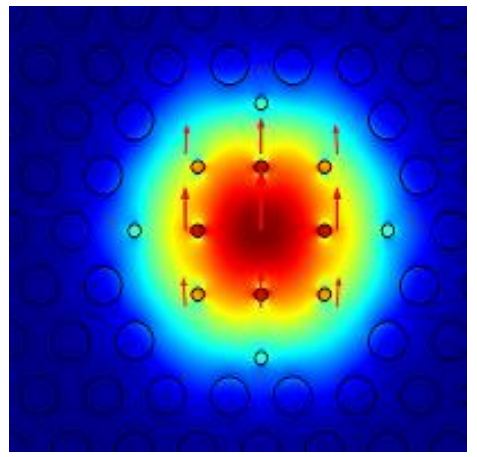

(b)

Fig. 3. Linearly polarized mode.

Zero dispersion photonic crystal fiber with very small core and efficient at generating supercontinuum light have been reported [50], [51]. By optimizing $d$ and $\Lambda$ it become possible to obtain zero dispersion with $\pm 1 \mathrm{ps} /(\mathrm{nm} . \mathrm{km})$ center approximately around $1.52 \mu \mathrm{m},(\mathrm{d}=0.73 \mu \mathrm{m}$ and $\Lambda=3.02 \mu \mathrm{m})$ [17]. Similarly, a dispersion of $D= \pm 0.5 \mathrm{ps} /(\mathrm{nm} . \mathrm{km})$ is achieved with $\mathrm{d}=0.63 \mu \mathrm{m}$ and $\Lambda=2.64 \mu \mathrm{m}$ [52]. This makes the fiber applicable for high data transmission. Also such fibers can be used supercontinuum generations. Dispersion behavior of the studied structures is shown in Fig. 4.

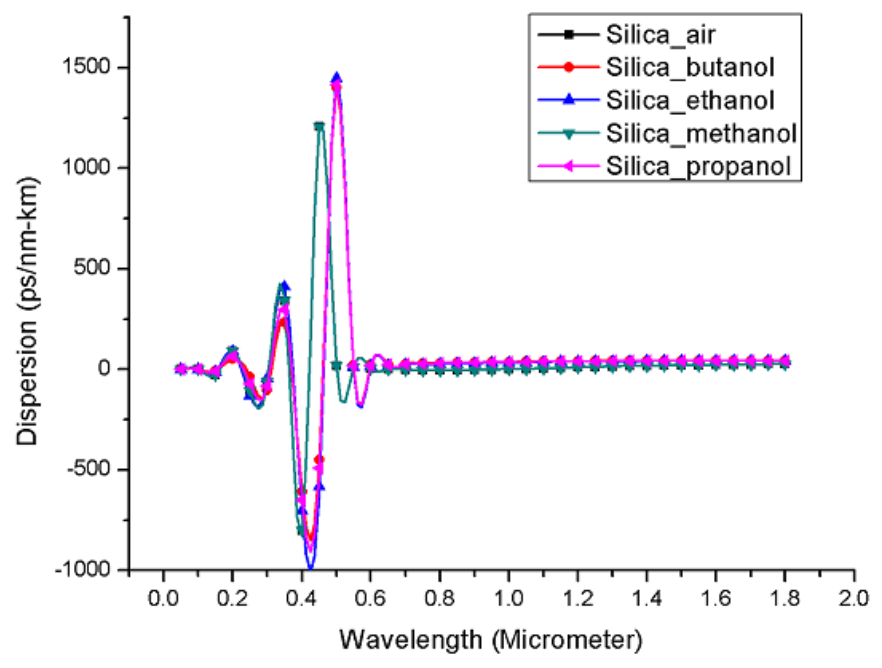

Fig. 4. Dispersion behavior.

Confinement loss at different wavelength have been plotted in Fig. 5. Do-octagonal structure with air hole has shown the highest loss in comparison to the doped do-octagonal PCF structure. However it is to be noted that the loss observed for all the structure is ultra low. The confinement loss obtained is of the order of $10^{-14}$. 


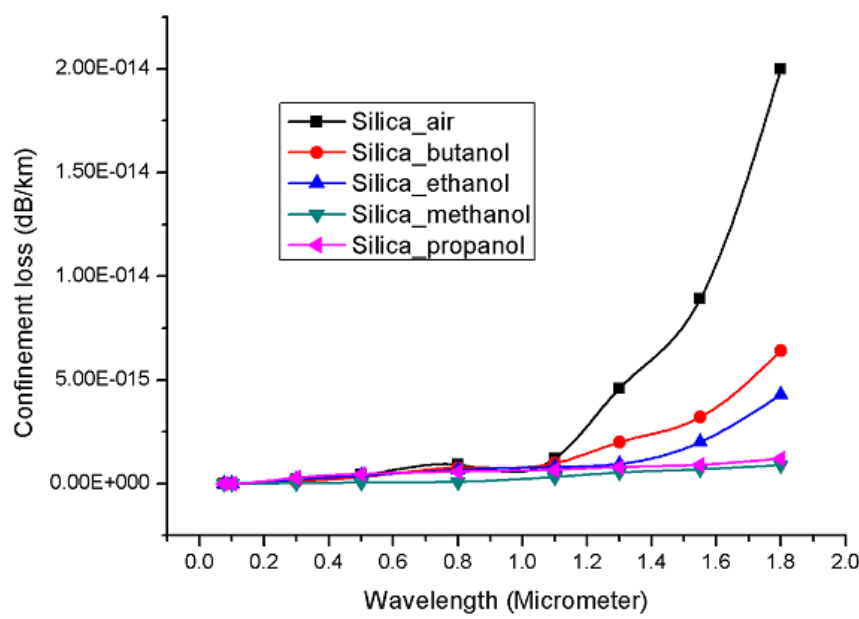

Fig. 5. Confinement loss obtained at different wavelength.

Do-octagonal PCF structure doped with methanol has the highest effective mode area in comparison to the other structures . Ethanol doped do-octagonal has the lowest effective mod e area in comparison to other structures. Figure 6 shows the effective mode area at different wavelength . Nonlinearity of a fiber is inversely proportional to the effective mode area. Nonlinearity of designed fiber is plotted in Fig. 7.

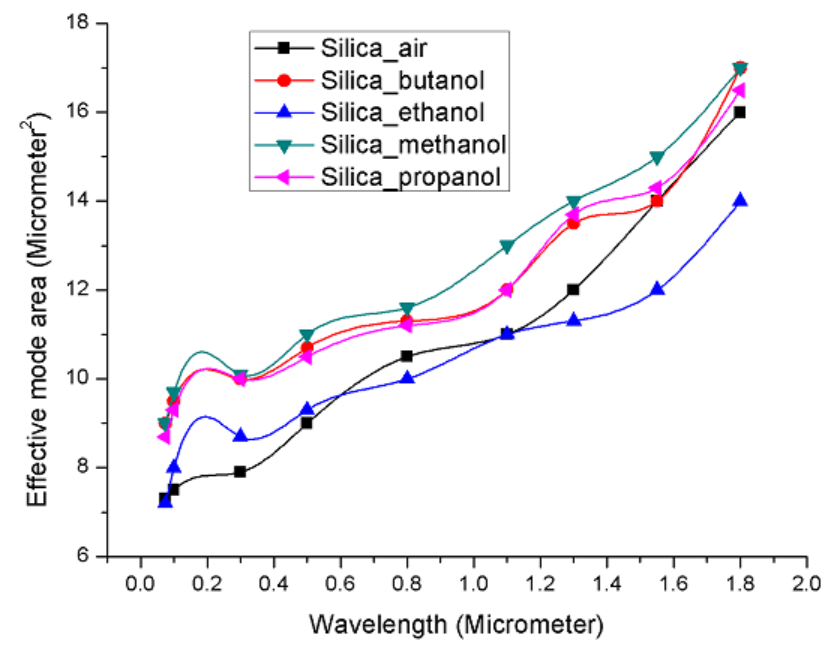

Fig. 6. Effective mode area. 


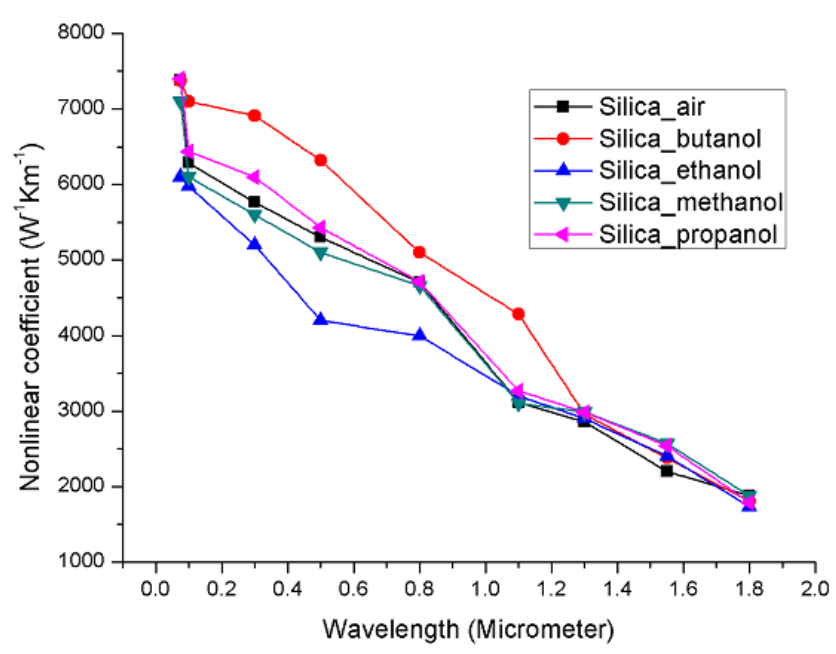

Fig. 7. Nonlinear coefficient observed in designed PCFs.

Supercontinuum generation has been explained with a PCF of length $15 \mathrm{~cm}$. In order to get desire characteristic of supercontinuum generation, zero dispersion wavelength of dispersion profile are important. Desire characteristics include width and flatness. Zero dispersion behavior has been obtained over a wide band of wavelength. Pump pulses at a wavelength of $1250 \mathrm{~nm}$ has been used for simulation. PCF has shown zero dispersion at this wavelength other values of different high order term of dispersion at $1250 \mathrm{~nm}$ are

$$
\begin{aligned}
& \beta_{2}=2.253 \mathrm{ps}^{2} / \mathrm{km}, \quad \beta_{3}=-1.401 * \times 10^{-2} \mathrm{ps}^{3} / \mathrm{km}, \quad \beta_{4}=4.010 * 10^{-5} \mathrm{ps}^{4} / \mathrm{km}^{-11} \\
& \beta_{5}=-9.419 \times 10^{-11} \mathrm{ps}^{5} / \mathrm{km}, \quad \beta_{6}=1.956 \times 10^{-14} \mathrm{ps}^{6} / \mathrm{km}, \quad \beta_{7}=-3.019 \times 10^{-16} \mathrm{ps}^{7} / \mathrm{km}, \\
& \beta_{8}=8.440 \times 10^{-19} \mathrm{ps}^{8} / \mathrm{km}, \quad \beta_{9}=-2.386 \times 10^{-21} \mathrm{ps}^{9} / \mathrm{km}, \quad \beta_{10}=1.186 \times 10^{-24} \mathrm{ps}^{10} / \mathrm{km} .
\end{aligned}
$$

Ultra short laser pulses with hyperbolic secant shape are introduced as the input to the PCF. These pulses equation can be characterize as:

$$
U(0, T)=\sqrt{P_{o}} \operatorname{sech}\left(\frac{T}{T_{o}}\right)
$$

Where $\mathrm{T}_{0}$ represents the temporal width of input pulse.

Higher order soliton become a dominant phenomena in the case of ultra short pulses pumped into zero dispersion regime. Soliton number determines these high order soliton. It can be calculated as:

$$
N^{2}=L_{D} / L_{N L}
$$

Here $L_{D}$ represent dispersion length and it is equal to $L_{D}=T_{0}^{2} /\left|\beta_{2}\right|$. Similarly $L_{N L}=1 / \gamma P_{0}$ where $L_{N L}$ is the nonlinear length. $P_{0}$ is the peak power used. $\beta_{2}$ is the group velocity dispersion coefficient. In Fig. 8, soliton numbers for the generation of supercontinuum are calculated against the variation of 
input pulse duration. It reveal that decrease in the duration of the input pulse leads to the generation of more number of high order soliton. Calculated soliton number are very large at the given peak power.

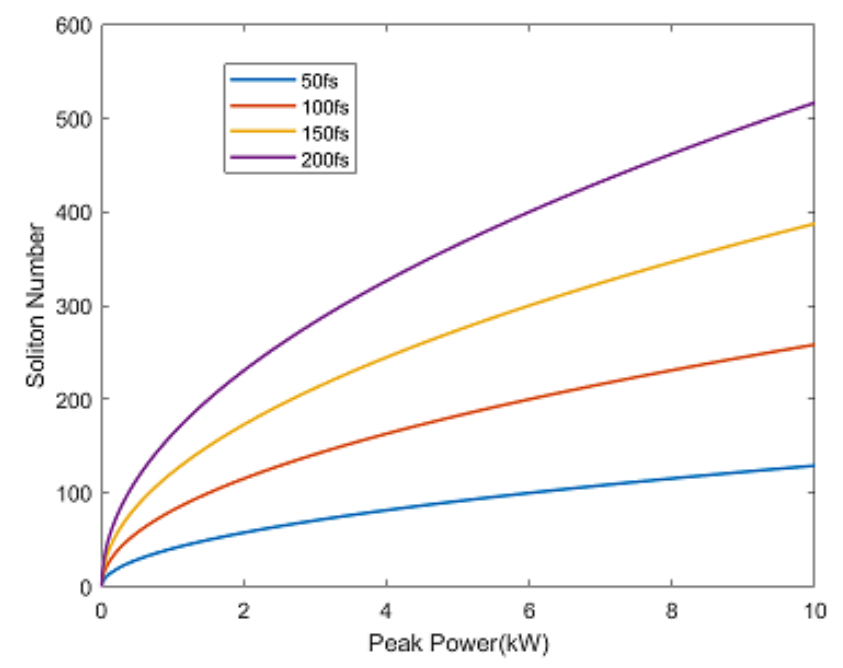

Fig. 8. Number of solitons generated at different input pulses.

Such a large generation of soliton may cause intra soliton interaction [53], [54]. Again dispersion length calculated is found to be $55 \mathrm{~cm}$. It shows much larger fiber than the actual fiber length of $15 \mathrm{~cm}$. Dispersion effect degrade in comparison to the nonlinear terms. Nonlinear effect determine the pulse evolution and result spectral broadening of these pulses.

Effect of pulse compression are affected by soliton fission length. These length are calculated using $L_{f i s s}=L_{D} / N$. The calculated value have been plotted in Fig. 9. Small duration of pulses cause in early pulse compression. It results smaller fission length and hence result wide spectrum.

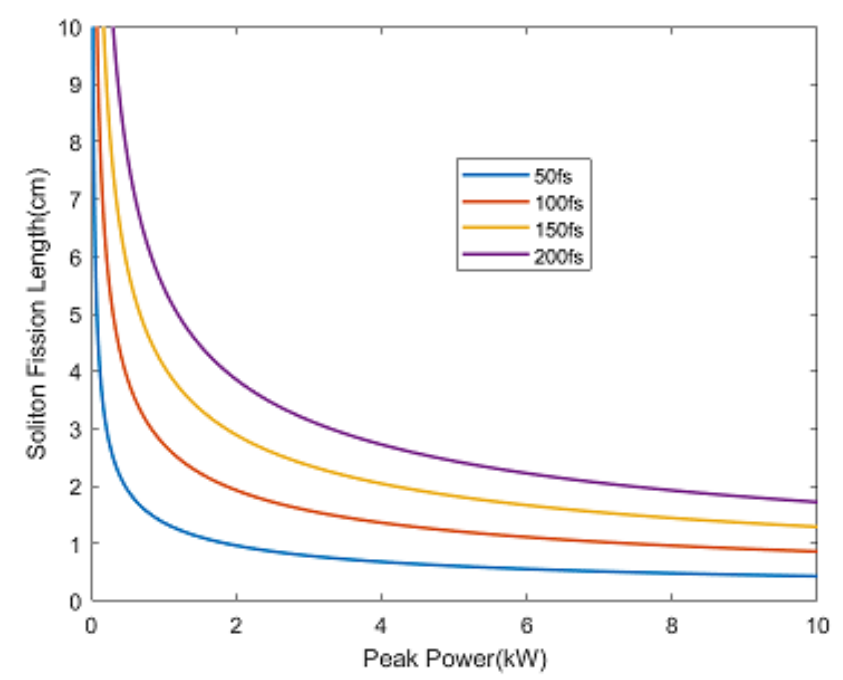

Fig. 9. Soliton fission length at different input pulses.

Optical pulse of duration $50 \mathrm{fs}$ at $1250 \mathrm{~nm}$ has been used in pumping pulse for supercontinuum generation. Numerical simulation for supercontinuum generation has been done at four different peak power levels $1 \mathrm{~kW}, 2 \mathrm{~kW}, 5 \mathrm{~kW}$ and $10 \mathrm{~kW}$ for air filled PCF structure. However, it can also be done for the liquid filled fibres, as also done previously by many researchers [55]-[58]. Liquid evaporation 
is an important limiting issue which prevents the realization of fiber for long term application in practical. Many application have been enabled by the feasibility of inserting gas, liquids, polymers, and colloids into the microstructure core fully or partially. It result and efficient interaction of the guided light and thus modifies the waveguide characteristics [59], [60]. However in some cases contact of the liquid with the external environment may degrade its properties. It is expected that very low fiber loss will not affect supercontinuum generation. First of all a numerical simulation for supercontinuum generation for fiber having different length have been perform by using pulse of $1 \mathrm{~kW}$ power. Fig. 10 (a) represent the spectral and temporal evolution of the input pulse of five different length of fiber respectively. A density plot has been used for getting more information about spectra broadening dynamic. Both spectral and temporal intensity have been plot using logarithmic density scale shorter at $-40 \mathrm{~dB}$ relative to maximum value. Fig. 10 (b) displays density plot. This plot is utilized for studying the low amplitude spectral and temporal components.
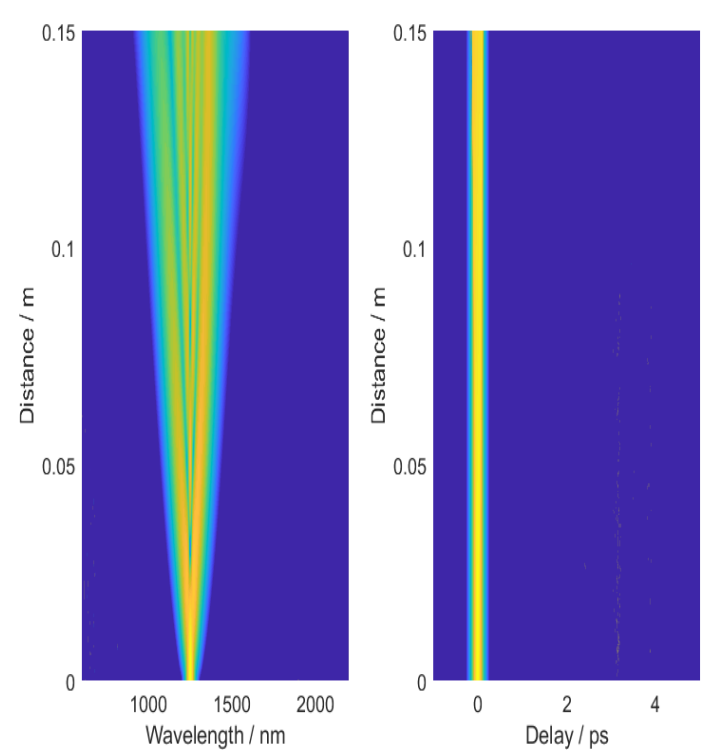

(a)

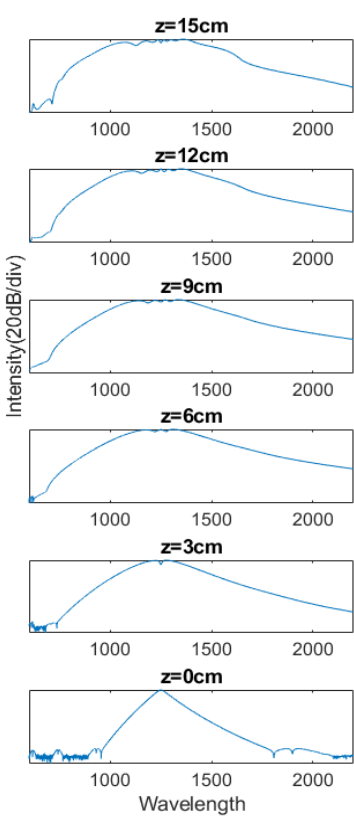

(b)

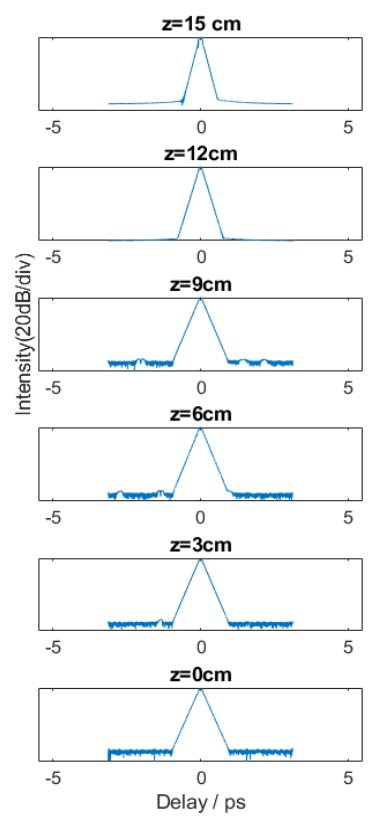

Fig. 10. Density plot of spectral and temporal profiles Fig. 10 (a) and Spectral profile and temporal profile Fig. 10 (b) of supercontinuum generation of a $15 \mathrm{~cm}$ long silica PCF at peak power of $1 \mathrm{~kW}$ with pulses of $50 \mathrm{fs}$ duration.

Initialy spectral broadening is dominated by modulation instability. Later it gets dominated by nonlinear phenomena like four wave mixing, dispersion wave generation, Raman scattering and self phase modulation. The spectrum obtained at the end of $15 \mathrm{~cm}$ fiber is $600 \mathrm{~nm}$ wide. Similarly more simulation has been made for supercontinuum generation by increasing the peak power to $2 \mathrm{~kW}, 5 \mathrm{~kW}$ and $10 \mathrm{~kW}$ respectively. The mechanism remain same except getting the wider broadening than in previous case. The spectral and temporal dynamic have been shown in Fig. 11 (a), Fig. 11 (b), Fig. 12 (a), Fig. 12 (b), Fig. 13 (a) and Fig. 13 (b) respectively.

The supercontinuum spectra obtained for peak power $1 \mathrm{~kW}, 2 \mathrm{~kW}, 5 \mathrm{~kW}$ and $10 \mathrm{~kW}$ are $600 \mathrm{~nm}$, $950 \mathrm{~nm}, 1450 \mathrm{~nm}$ and $2050 \mathrm{~nm}$ respectively. 

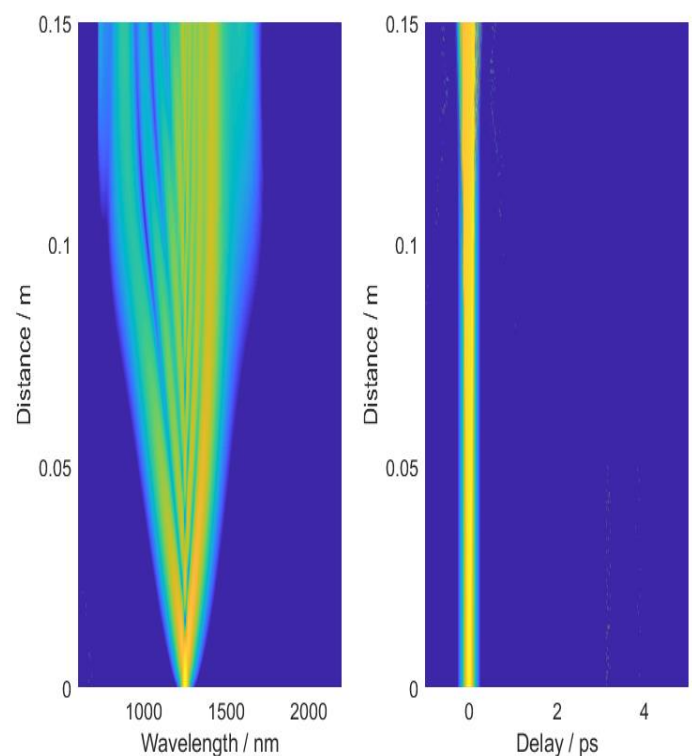

(a)
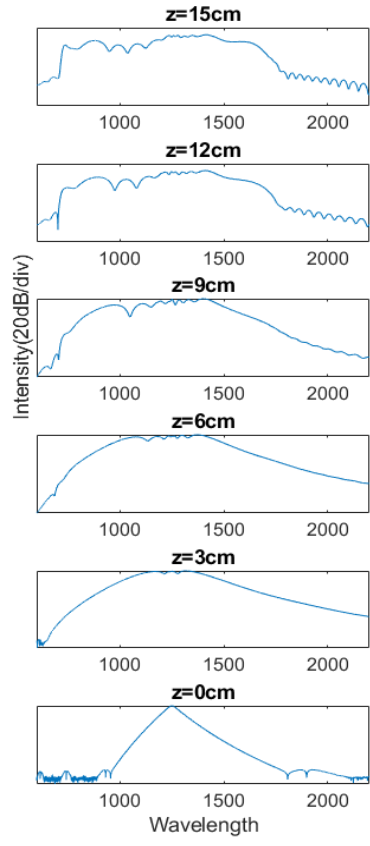

(b)

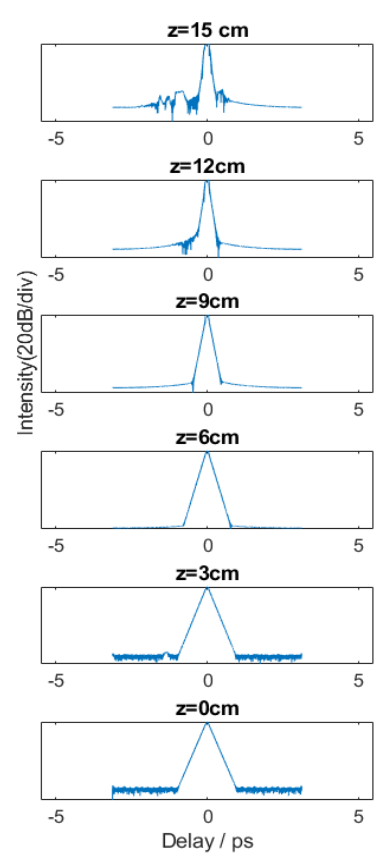

)

Fig. 11. Density plot of spectral and temporal profiles Fig. 11 (a) and Spectral profile and temporal profile Fig. 11 (b) of supercontinuum generation of a $15 \mathrm{~cm}$ long silica PCF at peak power of $2 \mathrm{~kW}$ with pulses of $50 \mathrm{fs}$ duration.
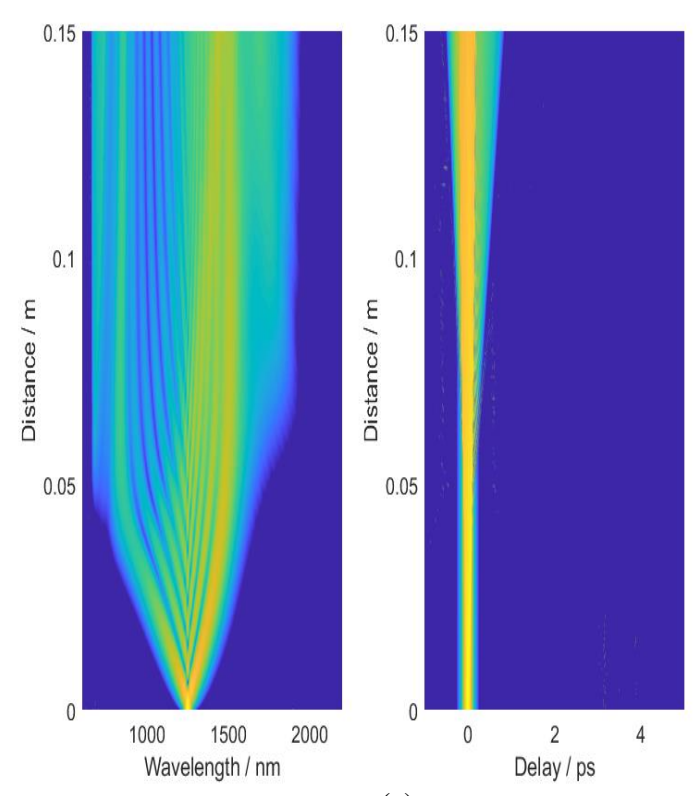

(a)

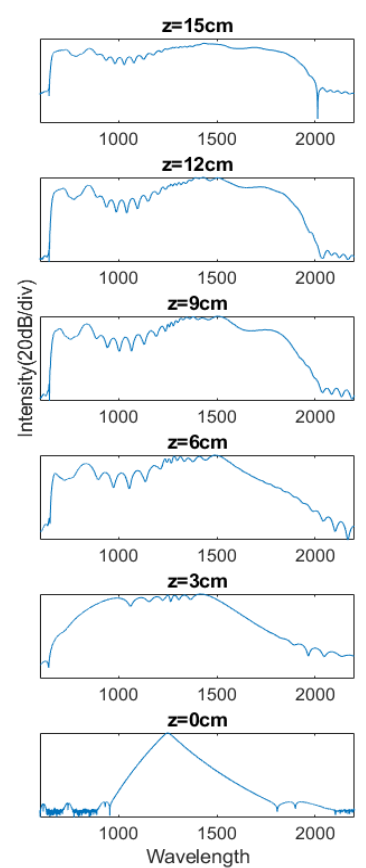

(b)
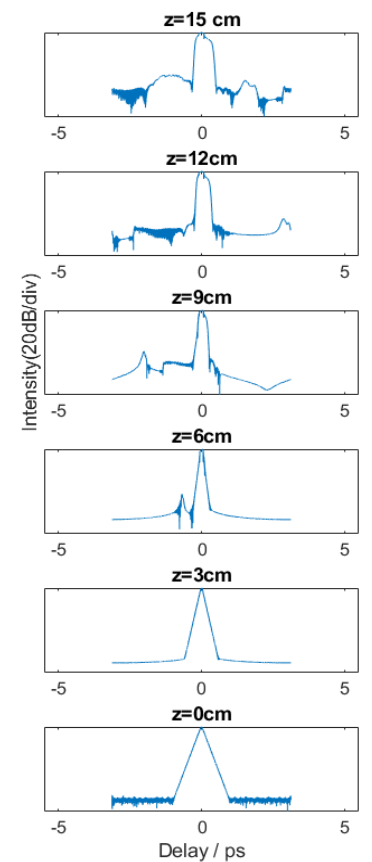

Fig. 12. Density plot of spectral and temporal profiles Fig. 12 (a) and Spectral profile and temporal profile Fig. 12 (b) of supercontinuum generation of a $15 \mathrm{~cm}$ long silica PCF at peak power of $5 \mathrm{~kW}$ with pulses of $50 \mathrm{fs}$ duration. 

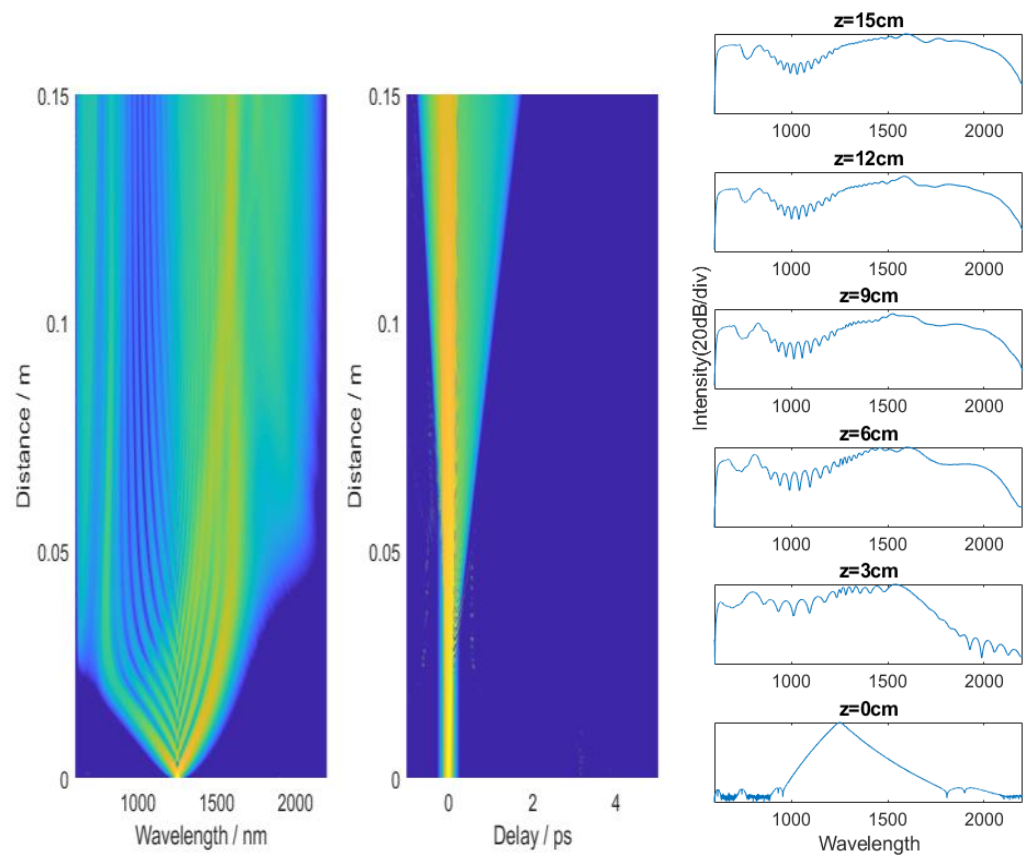

(a)

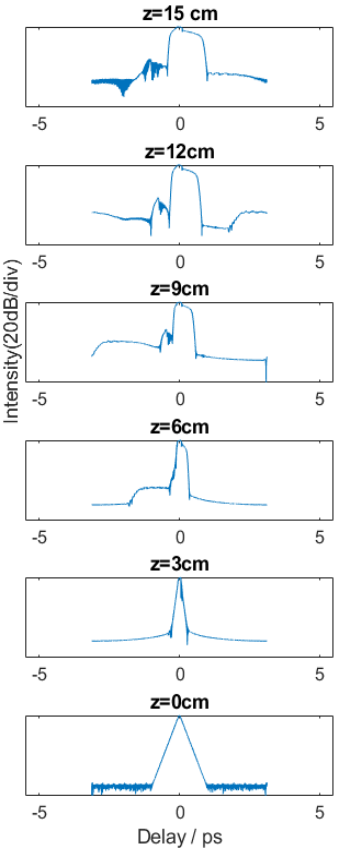

(b)

Fig. 13. Density plot of spectral and temporal profiles Fig. 13 (a) and Spectral profile and temporal profile Fig. 13 (b) of supercontinuum generation of a $15 \mathrm{~cm}$ long silica PCF at peak power of $10 \mathrm{~kW}$ with pulses of $50 \mathrm{fs}$ duration

Results obtained in this paper are compared with the previously reported results of PCF structures at the wavelength $1.33 \mu \mathrm{m}$. This comparison is tabulated in Table II.

TABLE II. COMPARISON OF OBTAINED RESULTS WITH PREVIOUSLY REPORTED PCF STRUCTURES AT $1.33 \mu \mathrm{m}$ WAVELENGTH.

\begin{tabular}{|c|c|c|c|c|c|}
\hline References & Birefringence & $\begin{array}{l}\text { Confinement } \\
\text { loss in } \mathrm{dB} / \mathrm{Km}\end{array}$ & $\begin{array}{l}\text { Dispersion in } \\
\text { ps/nm-km }\end{array}$ & $\begin{array}{c}\text { Effective mode } \\
\text { area in } \\
\left(\text { Micrometer }^{2}\right)\end{array}$ & $\begin{array}{c}\text { Nonlinear } \\
\text { coefficient in } \mathbf{W}^{-} \\
{ }^{1} \mathbf{K m}^{-1} \\
\end{array}$ \\
\hline Ferhat et al. [61] & -- & -- & 30 & 4.3 & 50 \\
\hline $\begin{array}{c}\text { Sharma et al. } \\
{[62]}\end{array}$ & -- & -- & 50 & 0.7 & 300 \\
\hline $\begin{array}{c}\text { Kirishna et al. } \\
\text { [63] }\end{array}$ & -- & -- & 100 & 4.3 & 50 \\
\hline $\begin{array}{c}\text { Ademgil et al. } \\
{[64]}\end{array}$ & 0.0019 & $2.1 * 10^{-2}$ & -- & -- & -- \\
\hline $\begin{array}{c}\text { Ademgil et al. } \\
{[65]}\end{array}$ & 0.00061 & $2.01 * 10^{-1}$ & -- & -- & -- \\
\hline Arif et al. [66] & 0.002825 & $2.07 * 10^{-6}$ & -- & -- & -- \\
\hline [Present Work] & 0.14 & $3.2 * 10^{-14}$ & Zero & 10.5 & 3430 \\
\hline
\end{tabular}

\section{CONCLUSION}

Do-octagonal PCF structure with holes arranged in rhombic fashion is investigated. These holes of circular dimension have been doped with different materials of alcoholic groups (-OH group). In one of the investigated structure holes are filled with air. Results of doped PCF structures are compared with PCF structure having air holes. Ultra flattened zero dispersion with much high birefringence has 
been achieved. Apart from this result, ultra low confinement loss with large nonlinearity has also been obtained. Number of solitons generated is large. Numerical simulation for supercontinuum generation has been performed. The supercontinuum spectra obtained for peak power $10 \mathrm{~kW}$ is $2050 \mathrm{~nm}$.

\section{REFERENCES}

[1] J. C. Knight, T. A. Birks, P. Russell, D. M. Atkin, “All-silica single mode optical fiber photonic crystal cladding”, Optics letters, vol. 21, pp.1547-1551, 1996.

[2] G. D. Kirishna, G. Prasanan, S. K. Sudheer, V. P. M. Pillai, "Analysis of zero dispersion shift and supercontinuum generation near IR in circular photonic crystal fibers”, Optik, vol. 145, pp. 599-607, 2017.

[3] G. K. M. Hasanuzzaman, Sohel Rana, M. S. Habib, "A novel low loss, highly birefringent photonic crystal fiber in $\mathrm{THz}$ regime", IEEE Photon. Technol. Lett., vol. 28, issue 8, pp. 899-902, 2016.

[4] Md. R. Hasan, Md. A. I., M. S. Anower, S. M. A. Razzak, "Low-loss and bend-insensitive terahertz fiber using a rhombicshaped core", Appl. Opt,. vol. 55, issue 30, pp. 8441-8447, 2016.

[5] M. E.-Heidari, F. Dehghan, H. Saghaei, F. Koohi-Kamali, M. Moravvej-Farshi, "Dispersion engineering of photonic crystal fibers by means of fluidic infiltration", J. Mod. Opt. vol. 59, issue 16, pp.1384-1390, 2012 .

[6] M. J. Steel, R. M. Osgood Jr., "Polarization and dispersive properties of elliptical-hole photonic crystal fibers", J. Lightwave Technol, . vol. 19, pp 495-503, 2001.

[7] D. Ferrarini, L. Vincetti, M. Zoboli, "Leakage properties of photonic crystal fibers", Opt. Express., vol. 10 pp.13141319, 2002.

[8] T. A. Birks, J. C. Knight, P. St, J. Russell, “Endlessly single-mode photonic crystal fiber”, Opt. Lett. Vol. 22, pp. 961963, 1997.

[9] H. Saghaei, V. Heidari, M. Ebnali-Heidari, M. R. Yazdani, "A systematic study of linear and nonlinear properties of photonic crystal fibers”, Opt. -Int. J. Light Electron. Opt., vol. 127, issue 24, pp.11938-11947, 2016.

[10] X. Freng, et al., "Single-Mode tellurite glass holey fibre with extremely large mode area for nonlinear applications", Opt. Express, vol. 16 (18), pp.13651-13655, 2008.

[11] T. P. Hansen, J. Broeng, S. E. B. Libori, E. Knudsen, A. Bjarklev, J. R. Jensen, H. Simonsen, "Highly birefringent index-guiding photonic crystal fiber" IEEE Photon. Technol. Lett., vol. 13, pp.588-590, 2001.

[12] L. Zhang, and C. Yang, "Photonic crystal fibers with squeezed hexagonal lattice", Optics Express, vol. 12, issue 11, pp. 2371-2376, 2004.

[13] S. Konar, S .K. Ghorai and Rakhi Bhattacharya; Highly Birefringent Microstructured Fiber with Zero Dispersion Wavelength at 0.64 Fiber and Integrated Optics 28, 138 (2009).

[14] J. K.Lyngso, B. J. Magnan, C. B. olaussan, P. J. Roberts, "7 cell hollow-core photonic crystal fibers with low loss in the spectral region around $2 \mu \mathrm{m} "$, Optic Express, vol. 17, issue 26, pp. 23468-23473, 2009.

[15] M. Cho, J. kim, H. Park, Y. Han, K. Moon, E. Jung, H. Han, "Highly birefringent terahertz polarization maintaining plastic photonic crystal fibers", Optics Express, vol. 16, issue 1, pp. 7-12, 2008.

[16] T. L. Wu, C. H. Chao, "A novel ultraflattened dispersion photonic crystal fiber”, IEEE Photon. Technol. Lett., vol. 17, pp.67-69, 2006

[17] A. Ferrando, E. Silvestre. P. Andres, J. Miret, M. Andres, "Designing the properties of dispersion-flattened photonic crystal fibers", Opt. Express, vol. 13, pp.687-697, 2001.

[18] K. Saitoh, M. Koshiba, T. Hasegawa, E. Sasaoka, "Chromatic dispersion control in photonic crystal fibers: application to ultra flattened dispersion", Opt. Express, vol. 11, pp. 843-852, 2003.

[19] X. Lei, "Highly nonlinear with low confinement losses square photonic crystal fiber based on a four-hole unit", Infrared Phy. Technol. , vol. 66, pp. 29-33, 2014.

[20] G. Jiang, Y. F, Y. Haung, "High birefringence rectangular- hole photonic crystal fiber", Optical Fiber Technology, vol. 26, part B, pp. 163-171, Dec., 2015.

[21] J-S Chiang, T-L Wu, "Analysis of propagation characteristics for an octagonal photonic crystal fiber (O-PCF)", Opt. Comm. Vol. 258, 2006.

[22] S. M. A. Razzak, Y. Namihira, F. Begum, S. Kaijage, N. Zou, "Design of a decagonal photonic crystal fiber with ultraFlattened chromatic dispersion”, IEICE Trans. Electron., E89-C(6), pp. 830-837, 2006.

[23] P. Kumar, Rohan, V. Kumar, J. S. Roy, "Dodecagonal photonic crystal fibers with negative dispersion and low confinement loss," Optik vol. 144, pp. 363-369, 2017.

[24] Q. Liu, S.Li, Jianshe Li, C. Dou, X. Wang, G. Wang, and Min Shi, “ Tunable Fiber Polarization Filter by Filling Different Index Liquids and Gold Wire Into Photonic Crystal Fiber”, Lightwave Technology, vol. 34, issue 10, pp. 2484-2490, May 15, 2016.

[25] Y. Lu, M.T.Wang, C. J. Hao, Z.Q. Zhao. J.Q. Yao, "Temperature sensing using photonic crystal fiber filled with silver nanowires and liquid", IEEE Photon. Journal. vol. 6, issue 3, June 2014.

[26] B. Sun - M.Y. Chen - Y.K. Zhang and J. Zhou , "Polarization-dependent coupling characteristics of metal-wire filled dual-core photonic crystal fiber", Opt Quant Electron vol. 47, pp. 441-451, April 2014.

[27] X Y.ang, Y. Lu, B. Liu, D. Xu and J. Yao ,Design of a Tunable Single-Polarization Photonic Crystal Fiber Filter with Silver-Coated and Liquid-Filled Air Holes", IEEE Photon. Journal, vol. 9, issue 4, August 2017.

[28] R.R. Singh and V. Priye, " Numerical analysis of filled loaded silicon nanowire optical rectangular waveguide and effective optical sensor”, Macro and Nano lettter, vol. 12, issue 9, pp. 1291-1294, September 2018. 
[29] F. Gui, P. Jiang, H. Yang, Y. Qiand W. Caiyang, "Design for a high birefringence photonic crystal fiber with multimode and low loss", Applied Optics, vol. 57, issue 1, pp. 6-13, January 2018.

[30] S. Liu, L. Jin, W. Jin, D. Wang, C. Liao, Y. Wang, "Structural long period gratings made by drilling micro-holes in photonic crystal fibers with a femtosecond infrared laser", Optics Express, vol. 18, issue 6 pp. 5496-5503, March 2010.

[31] Md. Waghmare, K. T. V.Reddy, "Design and Modal Analysis of Photonic Crystal Fiber for Dispersion Compensation over Broadband Range", Journal of Microwaves, Optoelectronics and Electromagnetic Applications, vol. 15, issue 4, pp. 365-379, December 2016 .

[32] J. Pniewski, T. Stefaniuk, G. Stepniewski, D. Pysz, T. Martynkien, R. Stepien, and R. Buczynski , "Limits in development of photonic crystal fibers with a subwavelength inclusion in the core", Optical Materials Express, vol. 5, issue 10, pp. 2366-2376 September 2015.

[33] A. Hartung, A. M. Heidt and H. Bartelt, "Design of all normal dispersion microstructured optical fibers for pulse preserving supercontinuum generation", Opt. Express, vol. 19, pp. 7742-7749, 2011.

[34] H. Saghaei, "Supercontinuum source for dense wavelength division multiplexing in square photonic crystal fiber via fluidic infiltration approach", Radio engineering, vol. 26, issue 1, pp.16-22, 2017.

[35] J. K. Ranka, R. S. Windeler, A. J. Stentz, "Visible continuum generation in air-silica microstructure optical fibers with anomalous dispersion at $800 \mathrm{~nm}$," Opt. Lett. Vol. 25, pp. 25-27, 2000.

[36] S. M. Abdur Razzak, Yoshinori Namihira, "Proposal for highly nonlinear dispersion flattened octagonal photonic crystal fibers", IEEE Photonics Technol. Lett., vol. 20(4), pp.249-251, 2008.

[37] A. Camerlingo, X. Feng, F. Poletti, G.M. Ponzo, F. Parmigiani, P. Horak, M.N. Petrovich, P. Petropoulos, W. H. Loh, D.J. Richardson "Near-zero dispersion highly nonlinear lead-silicate W-type fiber for application at 1.55um", Opt. Exp. Vol. 18(15), pp.15747-15756, 2010.

[38] F. Zolla, G. Renversez, A. Nicolet, "Foundations of photonic crystal fibers", world scientific press, science, 2005.

[39] John D. Joannopoulos, Steven G. Johnson, Josgua N. Winn, Robert D. Mede, Photonic crystal fiber: Molding the flow of light, $2^{\text {nd }}$ edition, Priceton University Press, 2008.

[40] Ajoy Ghatak, K. Thyagarajan, "Introduction to Fiber optics", $1^{\text {st }}$ South Asian Edition 1999.

[41] F. Poli, A. Cucinotta, S. Selleri, "Photonic crytal fibers properties and applications", Springer series in materail sciences, 2007

[42] M. Dudley. G. Genty, S. Coen, "Supercontinuum generation in photonic crystal fiber", Rev. Mod. Phys, vol. 78, issue-4, pp. 1135-1141, 2006.

[43] J. M. Dudely, J. R. Tylor, "Supercontinuum generation in optical fibers", Cambridge University Press, Cambridge, UK, 2010.

[44] Md. F. H. Arif *, Md. J. H. Biddut "A new structure of photonic crystal fiber with high sensitivity, high nonlinearity, high birefringence and low confinement loss for liquid analyte sensing applications"Sensing and Bio-Sensing Research, vol.12, pp. 8-14, November 2017.

[45] M. Morshed, Md. I Hasan, T. K. Roy, M. S. Uddin, S. M. A. Razzak, "Microstructure core photonic crystal fiber for gas sensing applications", Applied Optics, Vol. 54, No. 29, pp. 8637-8643, Oct., 2015.

[46] Md.I. Islam, K. Ahmed, S. Asaduzzaman, B. K. Paul, T. Bhuiyan, S. Sen, Md. Shadidul Islam a, Sawrab Chowdhury "Design of single mode spiral photonic crystal fiber for gas sensing applications", Sensing and Bio-Sensing Research, vol. 13, pp. 55-62, March 2017.

[47] S. Jiao, S. Jhang, "Improved scheme for the determination of a methanol using two dimensional photonic crystal", Instrumentation Science and Technology, Vol. 46, No. 2, pp. 175-184, Dec., 2017.

[48] P. Kumar, V. Kumar, J. S. Roy, "Design of quad core photonic crystal fiber with flatteneed zero dispersion", International Journal of Electronics Communicationtios (AEU), Vol. 98, pp. 265-272, Nov. 2018.

[49] W. J. Reeves, J. C. Knight, "Demonstration of ultraflattened dispersion in photonic crystal fibers", Optics Express, vol. 10, No. 14, pp. 609-613, July, 2002.

[50] W.J. Wadsworth, A. Ortigosa-Blanch, J.C. Knight, T.A. Birks, T-P.M. Man and P.St.J. Russell, "Supercontinuum generation in photonic crystal fibers and optical fiber tapers - A novel light source,” J. Opt. Soc. Am. B in press, (2002).

[51] J.C. Knight, J. Arriaga, T.A. Birks, A. Ortigosa-Blanch, W.J. Wadsworth, and P.St.J Russell, “Anomalous dispersion in photonic crystal fiber," IEEE Photon. Technol. Lett. 12, 807-809 (2000).

[52] A. Ferrando, E. Silvestre, J.J. Miret, and P. Andres, "Nearly zero ultra flattened dispersion in photonic crystal fibers," Opt. Lett. 25, 790 (2000).

[53] M. Sharma, S. Konar, "Three octave spanning supercontinuum by red-shifted dispers wave in photonic crystal fibers", Journal of Modern Optics, pp. 1-10, 2015.

[54] G. P. Agrawal, "Nonlinear Fiber Optics", (Academic Press, 2011).

[55] L. Tien, L. Wei, F. Guoying, "Numerical simulation of supercontinnuum generation in liquid filled photonic crystal fiberswith a normal flat dispersion profile", Optics Communications, Vol. 334, pp. 196-202, Aug., 2015.

[56] L. Tien, L. Wei, F. Guoying, "Numerical simulation for optimizing mode shaping and supercontinuum flatness of liquid filled seven core photonic crystal fibers", Optics Communications, Vol. 343, pp. 91-96, Jan., 2015.

[57] R. V. J. Raja, A. Husakou, J. Hermann, K. Porsezain, "Supercontinuum generation in liquid filled photonic crystal fiber with slow non linear response", J. Opt. Soc. Am. B, Vol. 27, No. 9, pp. 1763-1768, Sept., 2010.

[58] R. Raei, M. E. Heidari, H. Saghaie, "Supercontinnum generation in organic liquid-liquid core cladding photonic crystal fiber in visisble and near infra red regions", Journal of the Optical Society of America B, Vol. 36, No.2, pp. 323-330, Feb., 2018.

[59] A.Bozolan1,2,*, R. M. Gerosa1, C. J. S. de Matos1, M. A. Romero2 and C. M. B. Cordeiro, "Sealed liquid-core photonic crystal fibers for practical nonlinear optics, nanophotonics and sensing applications", SPIE, Vol. 7839, October 2010. 
[60] M.Sorahi-Nobar, A. Maleki-Javan ,"Supercontinuum Generation for Ultrahigh-Resolution OCT via Selective Liquid Infiltration Approach", Radio Engineering, vol. 27, issue 1, pp. 16-21, April 2018.

[61] M. L. Ferhat, L. Cherbi, I. Haddouche, "Supercontinnum generation in silica photonic crystal fiber at $1.3 \mu \mathrm{m}$ and $1.65 \mu \mathrm{m}$ wavelength for optical coherence tomography", Optik, vol. 152, pp. 106-115, 2018.

[62] M. sharma, S. Konar, R. K. khan,"Supercontinuum generation in highly nonlinear hexagonal photonic crystal fiber at very low power", Journal of Nanophotonics, vol. 9, pp.1-8, 2015.

[63] G. D. Kirishna, G. Prasanan, S. K. Sudheer, V. P. M. Pillai, "Analysis of zero dispersion shift and supercontinuum generation near IR in circular photonic crystal fibers", Optik, vol. 145, pp. 599-607, 2017.

[64] H. Ademgil, S. Haxha, "PCF based sensor with high sensitivity high birefringence and low confinement losses for liquid analyte sensing applications", Sensors, vol. 15, issue 12, pp. 31833-31842, 2015.

[65] H. Ademgil, S. Haxha, "Highly birefringent nonlinear PCF for optical sensing of analytes in aqueous solutions", Optik, vol. 127, issue 16 , pp. 6653-6660, 2016.

[66] Md. F. H. Arif, Md. J. H. Biddut, "Enhancement of relative sensitivity of photonic crystal fiber with high birefringence and low confinement loss", Optik, vol. 131, pp. 697-704, 2017. 